\title{
A FUNÇÃO SOCIAL DO MAGISTRADO FRENTE À INTERNACIONALIZAÇÃO DO DIREITO: um desafio à concretização dos direitos humanos? ${ }^{1}$
}

\author{
Mateus Tiago Führ Müller ${ }^{2}$
}

\begin{abstract}
RESUMO: Com a promulgação da Constituição Federal de 1988, o Brasil incorporou à sociedade nacional os princípios inerentes ao Estado de Direito e à Democracia, reconfigurando o modo de ver e entender o cidadão nacional. Essa reconfiguração representou não só um alargamento do rol de direitos e garantias fundamentais, como também criou novos deveres e funções ao cidadão, que se viu impelido a tomar postura ativa na resolução dos conflitos de uma sociedade que a cada dia que passa se torna mais complexa e plural. Em consequiência disso, houve, além de um incremento no número de ações, uma forçosa necessidade de o Judiciário dar resposta a esses novos e diversos conflitos resultantes da complexidade social, reconfigurando também a função social do magistrado, notadamente no âmbito de um processo constitucional.
\end{abstract}

PALAVRAS-CHAVE: Direitos Humanos; Magistrado; Internacionalização; Jurisdição constitucional.

\section{The Social Function of the Magistrate Front Internationalization of Law: a challenge to the implementation of human rights?}

\begin{abstract}
With the promulgation of the Constitution of 1988, Brazil entered the national society to the principles inherent in the rule of law and democracy, reconfiguring the way we see and understand the nationals. This reconfiguration represents not only an extension of the list of fundamental rights and guarantees, but created new functions and duties of the citizen, he had to take an active attitude in solving conflicts in a society that every day becomes more complex and plural. As a result, there was also an increase in the number of shares, a forceful need for the judiciary to meet these new and different conflicts in social complexity, also reconfiguring the social function of the magistrate, especially in a constitutional process.
\end{abstract}

KEY-WORDS: Human Rights; Magistrate; Internationalization; Constitutional Jurisdiction.

\section{INTRODUÇÃO}

Há três séculos, Cesare Beccaria denunciou o desequilíbrio social ao qual a sociedade ocidental à época estava inserida, na qual uma minoria privilegiada detinha para si, contra uma maioria debilitada e miserável, todo o poder e felicidade. Nessa sociedade desigual, não muito distante da qual estamos todos inseridos na contemporaneidade, somente ao comércio interessava, servindo como meio delimitador,

\footnotetext{
${ }^{1}$ Este artigo resulta do projeto de pesquisa intitulado "A Concretização dos Direitos Humanos na Jurisdição Brasileira sob a ótica do Constitucionalismo e da Internacionalização do Direito: o fenômeno da Recepção e da Fertilização Recíproca", vinculado à Universidade do Vale do Rio dos Sinos e coordenado pela Professora Doutora Jânia Maria Lopes Saldanha.

${ }^{2}$ Graduando em Ciências Jurídicas e Sociais na UNISINOS. Bolsista de Iniciação Científica vinculado aos Grupos de Pesquisa "Teoria Crítica do Processo" e "Delmas-Marty: Internacionalização do Direito e Emergência de um Direito Mundial". E-mail: mateustfmuller@gmail.com.
} 
segundo o nobre autor italiano, das relações que se travavam entre súditos e soberano (e as sociedades entre si). Como saída, Beccaria encerra a questão dizendo que somente boas leis impediriam tal disparate, pois todas as vantagens da sociedade seriam distribuídas equitativamente entre os membros que a compõem, sendo necessário, para tanto, "sustentar os direitos do gênero humano" (BECCARIA, 2007, p. 18).

Desse modo, frutos de um processo evolutivo histórico de lutas e conquistas, os Direitos Humanos (ou direitos do gênero humano, como preferia Beccaria) são hoje o fundamento das constituições democráticas modernas (BOBBIO, 1992). E assim, sob a égide do Estado Democrático de Direito, após longos vinte e um anos de autoritarismo (de 1964 a 1985), o Brasil viu na Carta Política de 1988 o nascedouro do mais longo período de democracia já vivido em solo pátrio. A democracia, no entanto, é a sociedade na qual os Direitos Humanos são protegidos e, além disso, na qual o cidadão tem garantido o acesso pleno aos seus direitos, seja através da participação ou da jurisdição.

Contudo, "o direito tornou-se num bem intercambiável" (GARAPON; ALLARD, 2005, p. 7), notadamente no que concerne aos direitos do Homem, sendo que cada vez mais as regras que norteiam a vida em uma sociedade servem para fundamentar o direito de outro país, colocando o magistrado no centro de um processo de internacionalização do Direito. Esse processo, portanto, forçou-o a tornar-se cidadão ativo na busca por novos marcos normativos e jurisprudenciais, para melhor fundar suas decisões.

Para explicar tal fenômeno, o presente artigo será dividido em duas partes. Na primeira, serão analisados aspectos doutrinários sobre o processo de desenvolvimento dos Direitos Humanos, evidenciando sua face universalizadora e pontuando alguns conceitos. Em seguida, será abordada brevemente a ainda latente discussão sobre o fundamento dos Direitos Humanos e a sua compreensão na contemporaneidade (2.1). E, como desdobramento dessa primeira parte, será evidenciado o tema (vital) da concretização desses direitos na atualidade (2.2), enfatizando, por fim, os desafios enfrentados pelo Poder Executivo (2.2.1) e pelo Poder Judiciário (2.2.2) na garantia da inviolabilidade dos Direitos Humanos frente à complexidade social que hodiernamente vivemos.

Na segunda, será demonstrado como se dá a participação dos juízes como motores de aplicação desses direitos na produção jurisprudencial brasileira, evidenciando que para uma melhor prestação da tutela jurisdicional há de se pensar 
contemporaneamente o Direito e o processo de forma crítica e aberta a novas propostas de solução de controvérsias (3.1), tendo como exemplo a bem sucedida condução da ADI 3510 enquanto paradigma brasileiro de aplicação do modelo coletivo de processo (3.2).

\section{OS DIREITOS HUMANOS COMO PARADIGMA DE UNIVERSALIZAÇÃO}

Como bem sustenta Norberto Bobbio (1992, p. 5), os Direitos Humanos, "por mais fundamentais que sejam, são direitos históricos, nascidos em certas circunstâncias"; resultados de lutas e conquistas, eles não nascem "todos de uma vez e nem de uma vez por todas" (BOBBIO, 1992, p. 5). Para Mireille Delmas-Marty (2003, p. 19), os direitos do Homem tratam, assim como a globalização econômica, "de um processo em curso, que possui as interrogações suscitadas pela sua aparente fragilidade"; difere da globalização, no entanto, "este processo, que se pode dizer 'de universalização', [pois] não tende à difusão de um modelo único, a partir de um ponto único, mas, sobretudo, à emergência, em diversos pontos, de uma mesma vontade de reconhecer os direitos comuns a todos os seres humanos" (DELMAS-MARTY, 2003, p. 19). Flávia Piovesan (2007a, p. 8), citando Hannah Arendt, sustenta que "os direitos humanos não são um dado, mas um construído, uma invenção humana, em constante processo de construção e reconstrução".

No entanto, José Afonso da Silva (2007, p. 175), em seu Curso de Direito Constitucional Positivo, sustenta que tendo em vista a ampliação e a constante transformação desses direitos do Homem no desenrolar da história - corrobora para esse entendimento o ensinamento do filósofo italiano Norberto Bobbio (1992, p. 30), que sustenta que os Direitos Humanos nasceram como direitos naturais universais, evoluíram como direitos positivos particulares e, por fim, encontraram sua realização plena como direitos positivos universais - , tornou-se difícil definir-lhes um conceito sintético e preciso.

E, além disso, essa dificuldade aumenta ao passo que para designá-los são empregadas várias expressões, "tais como: direitos naturais, direitos humanos, direitos do homem, direitos individuais, direitos públicos subjetivos, liberdades fundamentais, liberdades públicas e direitos fundamentais do homem" (SILVA, 2007, p. 175, grifos do autor). São todas essas expressões, pois, utilizadas para designar uma mesma categoria jurídica: os Direitos Humanos Fundamentais. 
Ingo Wolfgan Sarlet (2007, p. 332 - 338) acrescenta que a moderna expressão Direitos Humanos Fundamentais evidencia a indissolúvel interdependência entre os Direitos Fundamentais e os Direitos Humanos. Além disso, o autor continua ensinando que essa expressão ressalta aos direitos humanos de matriz internacional a fundamentalidade em sentido material dos direitos fundamentais de matriz constitucional, ou seja, outorga aos Direitos Humanos o privilégio do mesmo tratamento jurídico dos Direitos Fundamentais, pois seu objeto de proteção condiz com a salvaguarda de certos valores e reivindicações essenciais ao cidadão (ser humano).

Assim sendo, cabe ressaltar uma pequena distinção, principalmente por que introduzida pelo constituinte e acentuada pelo reformador constitucional da $\mathrm{EC} \mathrm{n}^{\mathbf{o}} 45$, entre o que se entende por Direitos Humanos e Direitos Fundamentais. Ademais, evidenciar até que ponto essas duas expressões significam categorias de direitos autônomos, porém interdependentes, pois são, além de tudo, direitos dos seres humanos.

Sarlet (2007) ensina que habitualmente um dos critérios que sustentam a distinção dada às expressões Direitos Humanos e Direitos Fundamentais é que a primeira guarda relação com os documentos de direito internacional, pois se refere àquelas posições jurídicas que reconhecem o ser humano como tal, independente de sua nacionalidade, e que, portanto, aspiram a uma validade universal, para todos os tempos e povos; enquanto a segunda, "se aplica para aqueles direitos do ser humano reconhecidos e positivados na esfera do direito constitucional positivo de determinado Estado" (SARLET, 2007, p. 333). Portanto, a expressão Direitos Humanos possui caráter supranacional, de Direito Internacional, enquanto Direitos Fundamentais, caráter nacional, de Direito Constitucional.

Essa distinção, segundo o mesmo autor (SARLET, 2007, p. 332 - 333), se evidencia em nossa Constituição Federal, a partir do constituinte, no Artigo $4^{\circ}$, inciso II, que estabelece como um dos princípios diretores das relações internacionais a prevalência dos Direitos Humanos; e, no Título II (Artigo $5^{\circ}$ e seguintes), arrolou o constituinte os direitos e garantias fundamentais do cidadão. O reformador acrescentou ao texto constitucional, acentuando essa distinção, o $\S 3^{\circ}$ do Artigo $5^{\circ}$, que dispõe sobre a regra a qual os tratados e convenções internacionais de Direitos Humanos estão submetidos para serem corretamente internalizados em nosso ordenamento jurídico, a fim de que tomem status de emendas constitucionais. Além disso, o reformador fixou a competência para processar e julgar as hipóteses de grave violação aos Direitos Humanos aos Juízes Federais, com a finalidade de salvaguardar que sejam cumpridas as 
obrigações decorrentes de tratados internacionais de Direitos Humanos dos quais o Brasil seja parte (Artigo 109, V-A e $\S 5^{\circ}$ da CF). Portanto, em princípio, não se trata de violação a todo e qualquer direito (fundamental ou não) positivado na Constituição, mas especificamente aos Direitos Humanos.

No entanto, essa evidenciação não exprime uma necessidade de apego à Lei, mas uma preocupação de se fazer notar a distinção que atualmente vige em nossa Carta Política e na Doutrina. Na defesa de uma efetiva aplicação e proteção dos Direitos Humanos, vale a lição de François Ost e Michel van de Kerchove, citada por José Ribas Vieira, de que "o Direito deva ser percebido não mais de modo kelseniano, mas sim em forma de rede" (VIEIRA, 2001, p. 161), porque, como bem evidencia Cançado Trindade (2007, p. XXXIII), os Direitos do Homem operam ostensivamente na defesa dos mais fracos, nas relações entre desiguais. Por isso, na ânsia de posicionar-se ao lado dos mais necessitados, a busca pela proteção dos direitos fundamentais do cidadão deve transpassar fronteiras jurídicas e buscar o princípio mais benéfico ao seu caso concreto.

A partir desse entendimento, para este artigo não se aplicam as diferenças suscitadas entre o que se entende por Direitos Humanos e Direitos Fundamentais, compreendendo, apesar de considerar inegável a distinção, os dois como defensores de um mesmo fim: a proteção do ser humano. Além disso, apesar de a Doutrina apontar distinções entre o que se entende por Direitos do Homem e Direitos Humanos, neste artigo serão entendidos como sinônimos, sem, no entanto, desconsiderar a lucidez dos doutrinadores em pontuar-lhes diferenças.

\subsection{O fundamento dos Direitos Humanos na contemporaneidade}

Portanto, como define Flávia Piovesan (2007b, p. 109), é evidente que a polêmica sobre o fundamento dos Direitos do Homem permanece intensa no pensamento contemporâneo, assim como sempre foi entre os filósofos.

Desse modo, Norberto Bobbio (1992), para saná-la, ensina que há três formas de se fundar os Direitos Humanos (ou de se fundar valores, como define): a primeira, deduzindo-os de um dado objetivo constante; a segunda, considerando-os como verdades evidentes em si mesmas; e, por fim, a terceira, consiste na aceitação de que em um determinado período histórico eles são geralmente aceitos, configurando, assim, o consenso. Esse autor, no entanto, se filia à terceira forma, assim como Flávia Piovesan e aqueles que advogam (como neste artigo) pela evolução histórica do reconhecimento dos Direitos do Homem. 
Assim, é correto dizer que a partir da Declaração Universal dos Direitos Humanos, aprovada pela Assembléia-Geral das Nações Unidas em 10 de dezembro de 1948, o problema do fundamento de certo modo se resolveu ${ }^{3}$ : a partir dela, a humanidade passou a partilhar alguns valores comuns, positivando e universalizando direitos. A positivação fez com que esses direitos fossem realmente protegidos, não mais apenas proclamados pelas nações; a universalização multiplicou os destinatários dos princípios contidos no rol de direitos e garantias, não mais sendo apenas os cidadãos de um Estado em específico, mas a Humanidade em geral, ou, como sustenta Bobbio (1992, p. 1), os cidadãos do mundo.

Esse movimento de positivar direitos universalmente aceitos é, portanto, a prova do consenso. E o consenso geral, por conseguinte, é a prova da validade dos documentos de Direitos do Homem. Logo, a conclusão deste silogismo é que Direitos Humanos são todos aqueles direitos e garantias do ser Humano que foram subjetivamente aceitos por toda a Humanidade e, assim, arrolados em documentos de cunho universal.

Isso tudo, portanto, é o que chamamos concepção contemporânea dos Direitos Humanos, introduzida pela Declaração Universal dos Direitos Humanos de 1948 e ratificada pela Declaração de Direitos Humanos de Viena de 1993 (PIOVESAN, 2007a, p. 8). É, portanto, o movimento de "somar a esfera nacional e a esfera internacional e avaliar a resultante à luz do princípio da prevalência dos direitos humanos e da primazia da pessoa" (PIOVESAN, 2009).

\subsection{A concretização dos Direitos Humanos na contemporaneidade}

Apesar de o problema do fundamento ter sido satisfatoriamente superado, é correto sustentar que sua efetividade deixa a desejar: carece, ainda, de vontade política a concretização desses direitos, não sendo suficiente seu simples arrolamento nas Constituições. A razão de ser dos Direitos Humanos é proteger o humano, não se basta, portanto, em um elenco de virtudes.

Nesse sentido, Jair Krischke (2002, p. 239 - 240), numa análise da parca ou nula efetividade na garantia dos Direitos Humanos por parte dos países da América Latina, tendo como base os abismos econômicos vividos nos países que a constituem e que por

\footnotetext{
${ }^{3}$ Segundo Norberto Bobbio (1992, p. 26), a Declaração Universal dos Direitos Humanos "representa a manifestação da única prova através da qual um sistema de valores pode ser considerado humanitariamente fundado e, portanto, reconhecido: e essa prova é o consenso geral acerca da sua validade".
} 
consequiência acabam por muitas vezes forçando uma despersonalização dos indivíduos pobres frente aos direitos que fundamentam a sua condição de cidadãos, levanta três hipóteses de falsas convicções em Direitos Humanos ${ }^{4}$ : a primeira é crer na possibilidade de poder aplicar harmoniosamente os princípios dos Direitos Humanos dentro de um mundo internacionalmente injusto sem que ninguém perca, ganhando todos: assegurar direitos aos mais fracos corresponde em afetar o poder dos mais fortes, seja econômica ou politicamente. A segunda tem relação com a igualdade e o caráter universal dos direitos humanos, pois em teoria todas as pessoas gozam de direitos humanos iguais, entretanto, na realidade e na prática, esses direitos têm se postado ao lado dos poderosos, violando, invariavelmente, os direitos dos pobres. E, a terceira, corresponde à "debilidade da conceituação liberal dos direitos humanos, no que concerne aos direitos econômicos, sociais e culturais" (KRISCHKE, 2002, p. 240), pois sem pão todas as liberdades se revelam existencialmente insignificantes.

É por isso, pois, que o mais urgente, hoje em dia, não é vencer o problema de fundar os Direitos do Homem (BOBBIO, 1992), mas o de concretizá-los: um desafio, portanto, ao Executivo e, em última análise, ao Judiciário.

\subsubsection{Um desafio ao Poder Executivo}

Pode-se sustentar que constitui um desafio ao poder Executivo a concretização dos direitos que fundamentam o cidadão nacional, porque necessita de minucioso planejamento político, econômico e financeiro para se alcançar a verdadeira distributividade na aplicação de todas as garantias fundamentais elencadas na Constituição Federal. A elaboração de programas de renda mínima, por exemplo, implicam investimento monetário em parcela da população que não atinge o limiar de uma renda média, mas, ao mesmo tempo, esse investimento não deve onerar excessivamente aqueles contribuintes que não são alvo desses programas a ponto de impedi-los de consumir ou constituir empresas, estagnando a economia estatal. Assim, neste caso, garantir um direito fundamental implica na dificuldade de garantir outro direito fundamental, gerando, de certo modo, um paradoxo.

\footnotetext{
${ }^{4}$ Num caminho menos pessimista, Flávia Piovesan traça sete desafios à concretização dos Direitos Humanos na ordem internacional contemporânea, retratando, desse modo, uma necessidade real e possível de superação das dificuldades impostas pelas relações de pressão estabelecidas entre a dinâmica das agendas dos mais variados grupos sociais e a estrutura estática dos Poderes Políticos dos Estados. Cf. PIOVESAN, Flávia. Direitos Humanos e Justiça Internacional: um estudo comparativo dos sistemas regionais europeu, interamericano e africano. 1. ed. 2. tiragem. São Paulo: Saraiva, 2007.
} 
No caso do exemplo anterior, a busca pela igualdade material financeira da população implica onerar outra parcela pelo aumento de tributos. Contudo, essa dificuldade é facilmente superada com o próprio texto constitucional, pois, como bem ele assevera, constituem objetivos fundamentais da sociedade brasileira erradicar a pobreza e reduzir as desigualdades, tanto sociais quanto regionais, além de promover o bem de todos, observados os preceitos da liberdade, da justiça e da solidariedade (Artigo $3^{\circ}$ da Constituição Federal). Portanto, é dever, e não faculdade, do Estado promover programas com a finalidade de realizar os objetivos da Nação brasileira.

No entanto, concernente à aplicabilidade dos Direitos Humanos de matriz universal em solo pátrio, o poder Executivo não só atua na concretização de direitos reivindicados pela sociedade nacional positivados em nossa Carta Magna, mas na garantia da realização de valores universalmente aceitos e arrolados em catálogos de Direito Internacional. Aqui, o desafio real não se encontra no ato de internalizar esses documentos políticos, que se constitui em desafio ao Poder Legislativo ${ }^{5}$, mas em fazer com que os direitos neles catalogados figurem num mesmo patamar de prioridade das garantias fundamentais constitucionais quanto à aplicabilidade, pois além daqueles direitos e garantias previamente arrolados na Constituição Federal, esses documentos inauguram mais alguns a serem tutelados pelo Estado, demandando mais esforço e planejamento político-econômico. É, portanto, um desafio consoante a Constituição Federal, de acordo com o $\$ 2^{\circ}$ do Art. $5^{\circ}$ da CF.

\subsubsection{Um desafio ao Poder Judiciário}

Com a consolidação do Estado-providência ${ }^{6}$, como ensina Boaventura de Sousa Santos (1997, p. 43), houve uma "expansão dos direitos sociais e, através deles, a integração das classes trabalhadoras nos circuitos do consumo anteriormente fora do seu

\footnotetext{
${ }^{5}$ Cabe ao legislador, por força da regra do $\$ 3^{\circ}$ do Artigo $5^{\circ}$ da $\mathrm{CF}$, equacionar as normas de Direito Internacional que versem sobre Direitos Humanos com o texto da Constituição Federal, buscando sempre preservar a vontade geral do povo nacional através da harmonização de ambos os ordenamentos jurídicos. O desafio do legislador, portanto, é fazer com que a norma ou princípio de direito humano internacional complemente e amplie o fundamento do cidadão nacional, sem suprimir o já largo rol de direitos e garantias fundamentais presentes na Carta Política de 1988. Pode-se sustentar, portanto, que ao Legislativo cumpre um desafio de proteção, mas não de concretização dos Direitos Humanos.

${ }^{6} \mathrm{~A}$ historicidade da formação do Estado brasileiro evidencia que nossa sociedade não passou pelo chamado Estado-providêcia (Welfare State). Conforme ensina Antonio Carlos Wolkmer (1990, p. 48), o Estado brasileiro "tem assumido diversas roupagens, ou seja, Estado Patrimonial-burocrático (Colônia), Estado Oligárquico (Império e Velha República), Estado Corporativista (Estado Novo, de 1937), Estado Populista (anos 40 e 50) e Estado Tecnocrático (Pós-revolução de 64)", findando com o atual Estado Democrático de Direito. Portanto, a explosão de litigiosidade brasileira se deu a partir da promulgação da Constituição Federal de 1988, momento histórico que proporcionou ao cidadão o acesso à justiça.
} 
alcance". No entanto, essa expansão veio a agravar-se ao final da década de 1970, quando um período de crescimento econômico cedeu espaço a uma recessão que se prolonga até hoje. Assim, houve uma "redução progressiva dos recursos financeiros do Estado e a sua crescente incapacidade para dar cumprimento aos compromissos assistenciais e providenciais assumidos para com as classes populares" (SANTOS, 1997, p. 44). Em conseqüência, isso implicou que os novos conflitos advindos dos novos direitos sociais fossem constitutivamente jurídicos, cuja dirimição caberia em princípio aos tribunais, resultando, por fim, numa "explosão de litigiosidade à qual a administração da justiça dificilmente poderia dar resposta" (SANTOS, 1997, p. 44).

Dessarte, a partir dessa explosão de litigiosidade, ${ }^{7}$ como um segundo desafio à concretização dos Direitos Humanos, o Estado passou a enfrentar uma situação paradoxal, pois além de ser o juiz, acabou por ser também o acusado quando se trata de garantir juridicamente a aplicabilidade dos direitos e garantias fundamentais (BICUDO, 2002, p. 14). Além disso, acrescenta-se a esse mais outro desafio, pois ao cidadão é permitido buscar a tutela tanto dos direitos universalmente catalogados (Art. $5^{\circ}, \S 2^{\circ}$, $\mathrm{CF})$ quanto àqueles constitucionalmente assegurados para defender-se de qualquer violação que sofrer.

Assim sendo, impõe-se uma abordagem de um ponto sensível sobre como se deve entender a função jurisdicional no Estado contemporâneo: a partir da relativização da soberania, ${ }^{8}$ alargou-se a possibilidade dos magistrados em julgar com base em normas não criadas em solo pátrio, garantindo ao cidadão a aplicabilidade de um direito

\footnotetext{
${ }^{7}$ Como exemplo, cito o Ministro da Saúde José Gomes Temporão que, debatendo sobre decisões jurídicas que obrigam o SUS a fornecer medicamentos específicos aos cidadãos, criticou a explosão de litigiosidade com o que chamou de "judicialização da saúde", em audiência pública realizada na Comissão de Seguridade Social e Família da Câmara dos Deputados. Cf. OLIVEIRA, Kelly. Ministro critica "judicialização da saúde". Agência Brasil, Brasília, 12 set. 2007. Disponível em: < http://www.agenciabrasil.gov.br/noticias/2007/09/12/materia.2007-09-12.2881071041/view>.

Acesso em: 17 ago. 2009.

${ }^{8}$ Quando se fala em concretização dos Direitos Humanos na contemporaneidade, há uma clara necessidade de, antes de tudo, se repensar a noção tradicional de soberania, primeiro fundamento do Estado brasileiro (Artigo $1^{\circ}$, I da $\mathrm{CF}$ ), pois não haverá como projetar uma agenda de garantias internacionais se os Estados continuarem a confinar ao interior de suas muralhas a competência exclusiva de delimitar aquilo que fundamenta a essência do cidadão (PIOVESAN, 2009). Além disso, só haverá uma efetiva e plena proteção e promoção dos direitos fundamentais quando ao cidadão for garantido buscar amplamente seus direitos nos mais variados catálogos de Direitos Humanos, extrapolando a esfera jurídica nacional. No entanto, cumpre salientar que a soberania, quando entendida como forma de expressão da vontade geral de um povo, como no Brasil, não deve ser suprimida, pois descaracterizaria a própria formação do Estado. Assim, quando para defender o indivíduo de atos exorbitantes desse poder soberano, cumpre à humanidade a salvaguarda dos direitos fundamentais inerentes a ele, tendo na esfera supranacional o rol de direitos necessários à sua proteção e, na nacional, o meio processual cabível para atuar contra o Estado, relativizando a soberania nacional através da harmonização dos ordenamentos jurídicos.
} 
que é dele, porém não criado por ele. Isso caracteriza um movimento que se pode dizer de internacionalização das fontes do Direito, que representa não só um alargamento de mentalidade, ${ }^{9}$ mas uma verdadeira ampliação da competência jurisdicional frente à garantia da inviolabilidade dos Direitos Humanos.

Desse modo, cumpre ao magistrado, que se encontra inserido nesse processo de internacionalização, fazer com que todos os direitos inerentes ao ser humano sejam assegurados sem que a soberania nacional seja atentada, sendo ele o agente harmonizador ${ }^{10}$ quando a jurisdição for provocada. É essa, portanto, a função social do magistrado frente às dificuldades de concretizar os Direitos Humanos dentro de uma sociedade cada vez mais complexa e plural. Como realizá-la, por conseguinte, será enfrentado na próxima parte deste artigo.

\section{O MAGISTRADO COMO MOTOR JURISDICIONAL DE UNIVERSALIZAÇÃO DOS DIREITOS HUMANOS}

Com o advento do contrato social o Estado passou a concentrar em si a competência para resolver os conflitos sociais através da jurisdictio. Assim, delegou ao magistrado o dever de realizar uma tutela jurídica correspondente ao que seria alcançado com a ação privada a partir de então proibida ao cidadão, investindo-o de poder jurisdicional. Esse poder, no entanto, contemporaneamente deve ser exercido somente na medida da lide proposta (Art. 128 do CPC), cabendo ao magistrado buscar nas provas produzidas em juízo e na interpretação da norma o meio cabível para dizer o direito dos cidadãos litigantes (ARENHART; MARINONI, 2008, p. 33).

No entanto, como as relações sociais tornaram-se mais complexas, a sociedade tomou um feitio mais aberto e plural. E assim, a jurisdição foi forçada a dar resposta às novas controvérsias surgidas dessa complexidade, impondo ao magistrado um dever de

\footnotetext{
${ }^{9}$ Hannah Arendt (1992, p. 274) ensina que a expressão mentalidade alargada traduz uma forma diversa de pensamento, a qual não se basta em estar em concórdia com o próprio eu, mas em ser capaz de pensar colocando-se no lugar de todas as demais pessoas. Esse entendimento vem a corroborar para a compreensão da universalização dos Direitos Humanos, pois, como bem assevera Mireille Delmas-Marty (2003, p. 8), "a universalidade implica um compartilhar de sentidos", ou seja, implica um compartilhar de fontes e experiências quando se tem por fim defender e promover os Direitos Humanos.

${ }^{10}$ A harmonização, como ensina Mireille Delmas-Marty (2003), é forma de fazer com que os sistemas se aproximem sem que as diferenças sejam todas suprimidas. Desse modo, é meio de internalizar os Direitos Humanos sem que estes suprimam direitos fundamentais legitimados por lutas e conquistas históricas do cidadão nacional, servindo, ainda, de apoio (ou meio ratificador) desses direitos fundamentais. A harmonização soma ao sistema jurídico interno o conjunto de princípios externos, sem, no entanto, substituir ou subtrair direitos e garantias nacionais, ordenando o múltiplo.
} 
busca por novas e diversas fontes, extrapolando, por muitas vezes, a esfera jurídica nacional. Essa complexidade não só incrementou as demandas mais comuns, mas atingiu patamares de interesse geral, versando principalmente sobre casos de violação dos direitos e garantias fundamentais de segunda e terceira gerações. ${ }^{11}$ Houve, a partir dessas ações de interesse difuso, uma sistemática constitucionalização do processo, que viu no seu modelo coletivo a melhor forma de responder a essas novas demandas: o tradicional modelo individualista, ao qual só interessa promover a felicidade das partes litigantes e que tem no processo de conhecimento de rito ordinário seu paradigma, apesar de uma aparente seguridade que oferece, neste caso não dá o suporte necessário para se prestar uma boa tutela jurisdicional, pois não é capaz de atingir a sociedade como um todo (SALDANHA; ESPINDOLA, 2008, p. 49 - 72).

Assim, tal como se apresenta hoje, a Teoria Geral do Processo não oferece meio suficiente para se implementar sem dificuldades o necessário modelo coletivo, pois privilegia para o direito positivo uma epistemologia de caráter positivista, de perfil privado e individualista (SALDANHA, 2007). Desse modo, a compreensão dos institutos processuais se dá no âmbito de um procedimento ordinário, de cognição plena e de matriz dogmática (SALDANHA, 2007), ou seja, no âmbito de um modelo individualista de processo.

O magistrado, para essa epistemologia, se mostra, conforme evidencia Calamandrei (1990), como um ator limitado em talento e energia, pois sua missão se restringe a somente escolher dentre os argumentos apresentados pelos advogados aquele que mais lhe agrada. Para conduzir o processo, portanto, basta que seja um homem médio e inerte (CALAMANDREI, 1990). Diferente desse, o magistrado que atua no âmbito de um processo de modelo coletivo, constitui-se em verdadeiro ator social, partícipe ativo para a concretização da paz e da justiça. Assim o é, pois privilegia ao processo decisões compartilhadas e impulsionadas por um diálogo vivo e aberto às novas e diversas interpretações para além daquelas ligadas aos intérpretes jurídicoformais da norma.

Evidencia-se, com essa nova atitude, uma necessária implementação de uma nova epistemologia à Teoria Geral do Processo, voltada, portanto, à concretização de um processo de modelo coletivo: na atual cultura positivista, pois, "nenhum Direito está de fato à altura desta reivindicação [...], todo Direito é particularizado, não realiza o

\footnotetext{
${ }^{11}$ O Brasil, além disso, através da ADI 3510, se inseriu também num rumo de proteção aos direitos de quarta geração, referentes à manipulação do patrimônio genético dos indivíduos (BOBBIO, 1992, p. 6).
} 
verdadeiro interesse geral, mas apenas o interesse médio de uma elite minoritária" (WOLKMER, 1994, p. 61). Essa dialética, portanto, surgida de uma "agudização" das contradições paradigmáticas e epistemológicas dos modelos processuais, nos leva a uma crise ainda não superada, e que perpassa todos os campos do saber jurídico.

\subsection{Crise, crítica jurídica e um novo processo}

Dessarte, tanto Leonel Severo Rocha (2008, p. 1035 - 1037) quando define a crise do Direito da modernidade quanto Jânia Maria Lopes Saldanha (2007) quando analisa a crise da Justiça, defendem que não se trata somente de um estado crítico da tradicional e deficiente estrutura do Poder Judiciário, mas de uma necessária superação de pressupostos dogmáticos, de uma necessária abertura e integração do Direito com a sociedade e suas instâncias decisórias não-jurídicas. Aqueles princípios oriundos das ciências exatas que influenciaram a produção do conhecimento jurídico (SALDANHA, 2007) já se mostram defasados “em relação a uma série de questões importantes da sociedade, em relação a problemas políticos decisivos e, principalmente, [...] quanto àquilo que chamamos novos Direitos” (ROCHA, L., 2008, p. 1036).

Essa crise, portanto, que "ocorre nos mais variados sistemas jurídicos do mundo ocidental, seja por sua morosidade, seja em razão do seu distanciamento para com as demandas da cidadania" (SALDANHA, 2007, p. 28), se deu a partir de quando se ingressou "numa nova forma de sociedade globalizada" (ROCHA, L., 2008, p. 1036), ou seja, numa sociedade pós-moderna, transnacionalizada. Por reflexo, no Brasil, onde a cultura jurídica é "marcada por uma tradição monista de forte influxo kelseniano, [...] cuja produção transforma o Direito e a Justiça em manifestações estatais exclusivas" (WOLKMER, 1994, p. 86), a crise se mostra profundamente paradigmática, "pois vê-se diante de novos e contraditórios problemas, não conseguindo absorver determinados conflitos coletivos específicos" (WOLKMER, 1994, p. 86). Assim, "o centralismo jurídico estatal montado para administrar conflitos de natureza individual e civil tornase incapaz de apreciar devidamente os conflitos coletivos de dimensão social" (WOLKMER, 1994, p. 86).

Desse modo, a partir desse novo quadro paradigmático de superação da Dogmática Jurídica de tradição monista, torna-se insustentável a manutenção do modelo kelseniano ainda defendido pelos neo-positivistas analíticos (ROCHA, 2008), dando, assim, ensejo a uma necessária crítica à atual epistemologia vigente na Teoria Geral do Processo e na teoria jurídica como um todo. Há que se acrescentar, portanto, à teoria 
jurídica, mecanismos que sejam capazes de permitir a influência de outras culturas no Direito, possibilitando-lhe, assim, uma auto-reprodução ${ }^{12}$ a partir de critérios mais abrangentes. Ou seja, uma crítica jurídica capaz de compreender o Direito como "um sistema aberto, dinâmico, que não se limita a uma formalização, abrindo-se para outros valores e novas formulações surgidas em cada procedimento, por tratar-se de um fenômeno relacional envolvendo seres humanos" (OLIVEIRA; MOTTA, 2008, p. 155).

Portanto, para compreendê-la, conforme define Leonel Severo Rocha (2008), pode-se dividi-la, genericamente, em duas etapas: numa primeira, preocupada em evidenciar a incompletude do normativismo frente às novas necessidades sociais; e, numa segunda, que se pode sustentar mais elaborada (e que mais importa a este artigo), preocupada em propor "uma nova hermenêutica para se pensar o Direito" (ROCHA, L., 2008, p. 1037). Essa nova hermenêutica surge "quando se percebe a insuficiência da noção de norma jurídica, e se começa a entendê-la como algo que não é completo, um conceito que é limitado, que deve ser complementado pela interpretação social" (ROCHA, L., 2008, p. 1037).

Desse modo, como resultante dessa crítica, pode-se sustentar que devem ser repensadas, na Teoria Geral do Processo, as estruturas processuais contemporâneas, de modo a fazer com que se aproximem juristas e sociedade, meios judiciais e extrajudiciais de solução de controvérsias. Como define Saldanha (2007, p. 31) em citação à lição de Castanheira Neves, "o que importa mesmo é a 'concreta realização do direito", e o meio utilizado para tanto é o Direito Processual. Assim, é preciso que os juristas passem a "pensar o que se deixa de aprender com outros espaços de solução de controvérsias" (SALDANHA, 2007, p. 28), para que se consiga, mais adiante, se pensar em um novo processo, um processo fundado em uma nova hermenêutica ${ }^{13}$, capaz de

\footnotetext{
${ }^{12} \mathrm{O}$ conceito de auto-reprodução nos permite observar o Direito como um sistema autopoiético, portanto, um sistema que opera "ao mesmo tempo 'fechado normativamente', o que garante sua manutenção e auto-reprodução, e 'aberto cognitivamente', no sentido de que está em contínua adaptação às exigências do ambiente" (MELLO, 2006, p. 356). Assim, constitui-se num sistema comprometido com "uma epistemologia construtivista que privilegie para a globalização a temática da pluralidade social, da complexidade, dos paradoxos e [dos] riscos" (ROCHA, L., 2008, p. 1036).

${ }^{13}$ Saldanha (2007) busca em Boaventura de Sousa Santos o conceito de hermenêutica diatópica para fundar sua argumentação de que se faz necessário ao processo e à jurisdição contemporâneos uma Teoria da Tradução, em detrimento da Teoria Geral do Processo. Essa hermenêutica, na visão de Boaventura de Sousa Santos, "funcionaria como facilitadora do diálogo" (SALDANHA, 2007, p. 44) entre os diferentes sistemas, as diferentes culturas. "A grande lição da hermenêutica diatópica é que os topoi de uma cultura são tão incompletos quanto ela própria. Assim, o objetivo da hermenêutica diatópica não é atingir a completude, mas ampliar a sua consciência de incompletude por intermédio de um diálogo" (SALDANHA, 2007, p. 44). Por fim, alcançaria a completude pela interpretação social, um "diferente processo de criação do conhecimento" (SALDANHA, 2007), privilegiando e exigindo uma construção coletiva, participativa e intersubjetiva (SALDANHA, 2007).
} 
manter-se aberta à interpretação social e à ampliação das suas "fontes de produção de sentido" (ROCHA, L., 2008, p. 1042).

Com base nisso, se tem que o modelo coletivo de processo, por que impulsionado por uma nova hermenêutica voltada à interpretação plural, promove uma abertura à participação de outros sujeitos para além daquelas figuras clássicas do modelo individualista (SALDANHA; ESPINDOLA, 2008, p. 49 - 72). Inaugura, portanto, uma nova fase, pois ao permitir o diálogo da Justiça com a sociedade através do processo, traduz-se em verdadeiro exercício de democracia direta (SALDANHA; ESPINDOLA, 2008, p. 49 - 72) e oportuniza um privilegiado espaço para se repensar os institutos e as estruturas processuais tradicionais.

\subsection{A ADI 3510 como paradigma de um processo de modelo coletivo}

Nesse sentido se postou a afamada ADI 3510, caso emblemático de internacionalização do Direito na jurisprudência brasileira recente, que tinha por fim declarar inconstitucional o Artigo $5^{\circ}$ da Lei 11.105/2005, a Lei de Biossegurança. Por maioria, a Corte Suprema decidiu que tal artigo não merecia reparo, permitindo, em maio de 2008, para fins de terapia e pesquisa, a utilização de células-tronco embrionárias obtidas de embriões humanos produzidos por fertilização in vitro e não utilizados no respectivo procedimento.

Para melhor elucidar a singularidade desse caso e o peso de tê-lo como exemplo, do voto do relator da ADI Ministro Carlos Ayres Britto, se extrai as seguintes palavras: "ao que se sabe, é a primeira vez que um Tribunal Constitucional enfrenta a questão do uso científico-terapêutico de células-tronco embrionárias" (BRITTO, 2008), cujo desfecho, em virtude da importância que tal ação detém, "é de interesse de toda a humanidade" (BRITTO, 2008). Assim, com base em tal afirmação e utilizando-se da ferramenta da transdisciplinariedade, o Supremo Tribunal Federal, em experiência inédita, convocou autoridades dos diversos campos do saber, para, em audiência pública, proferirem seus pareceres sob o prisma das disciplinas que representam. Tal alargamento de mentalidade configura não só uma caminhada em direção à democracia direta, mas um início de abertura a novas e diferenciadas formas de interpretação constitucional que os tribunais vêm se inserindo.

Peter Häberle (1997, p. 13), jurista alemão, ensina que "os critérios de interpretação constitucional hão de ser tanto mais abertos quanto mais pluralista for a sociedade". E que numa sociedade de relações complexas e de natureza plural, a 
interpretação constitucional não deve ser condicionada a uma sociedade fechada dos “intérpretes jurídicos 'vinculados às corporações' (zünftmässige Interpreten) e aqueles participantes formais do processo constitucional" (HÄBERLE, 1997, p. 13) (modelo individualista), mas aberta a "todos os órgãos estatais, todas as potências públicas, todos os cidadãos e grupos, não sendo possível estabelecer-se um elenco cerrado ou fixado com numerus clausus de intérpretes da Constituição" (HÄBERLE, 1997, p. 13) (modelo coletivo). Assim, essa postura adotada pelo STF denota um movimento de abertura à pluralidade que a sociedade jurídica brasileira vem se inserindo, importando ao processo jurídico (notadamente ao de cunho constitucional), além das normas de Direito nacional, os diversos dogmas religiosos, os rumos das pesquisas científicas, os posicionamentos políticos e o debate ético gerado em torno do caso concreto, conferindo à decisão maior legitimidade perante a sociedade como um todo.

Mas os Ministros do STF não se bastaram apenas com as leis nacionais e as informações colhidas da audiência pública para acordarem e darem resposta final ao caso: buscaram também nas fontes normativas e jurisprudenciais estrangeiras e internacionais a base necessária para que, junto das normas, costumes e princípios de Direito brasileiros, proferissem a melhor decisão à ADI 3510.

Tomemos como exemplo os votos das Ministras Cármen Lúcia (2008) e Ellen Gracie (2008), e dos Ministros Gilmar Mendes (2008) e Ricardo Lewandowski (2008). Cármen Lúcia fundou seu voto para além dos marcos normativos e jurisprudenciais nacionais, citando o art. $4^{\circ}$ do Pacto de São José da Costa Rica; o preâmbulo e o art. $1^{\circ}$ da Declaração Universal dos Direitos Humanos de 1948; os arts. $1^{\circ}, 10$ e 11 da Declaração Universal sobre o Genoma Humano e os Direitos Humanos da UNESCO de 1998; o preâmbulo da Carta das Nações Unidas de 1945; o art. $3^{\circ}$ da Declaração dos Direitos das Pessoas Deficientes de 1975; e o item 6 da Declaração da Conferência da ONU no Ambiente Humano de Estocolmo de 1972. Ellen Gracie, então presidente do Supremo Tribunal Federal, nessa mesma esteira, citou o marco normativo estrangeiro Human Fertilisation and Embryology Act do Reino Unido, internacionalizando também o seu embasamento jurídico.

Gilmar Mendes e Ricardo Lewandowski foram mais longe: buscaram seus fundamentos não só nas fontes de Direito brasileiro ou em catálogos de Direito Internacional, mas também em normas e jurisprudências estrangeiras. O primeiro, além de citar fontes de Direito nacional e internacional, também fundou sua decisão naquelas de Direito estrangeiro, dentre as quais se destacam o art. $2^{\circ}$, II, da Lei Fundamental e a 
lei sobre a importação e utilização de células-tronco (Stammzellgesetz) alemãs; a Lei de Bioética francesa, de 6 de agosto de 2004; a Lei Espanhola no 14, de 3 de julho de 2007; e a Lei Geral de Saúde do México, de 7 de fevereiro de 1984. Além disso, como exemplo, citou as sentenças 53/1985, 212/1996 e 116/1999 da jurisprudência espanhola, a decisão da Suprema Corte estadunidense no caso Roe vs. Wade, e as decisões do Tribunal Constitucional alemão sobre aborto (BVerfGE 39, 1, 1975; BverfGE 88, 203, 1993). Nesse mesmo caminho, o segundo utilizou-se de largo rol de referências normativas não-nacionais. A título de exemplo, destacam-se a lei federal suíça de 1998; o Relatório elaborado pelo Human Embryo Research Panel dos Estados Unidos da América em 1994; o Convênio sobre Direitos Humanos e Biomedicina do Conselho da Europa; o Código de Saúde Pública francês; a Lei Francesa de 29 de julho de 1994; as Leis alemãs de proteção ao embrião (Embryonenschutzgesetz) e das células-tronco (Stammzellgezetz); as Leis 35/1988, 45/2003 e 14/2007 e o Código Penal espanhóis; e o Genetic Information Nondiscrimination Act, aprovado pelo Congresso estadunidense. Além disso, em seu voto fez referência às decisões da Corte Constitucional da Espanha sobre proteção à vida humana, especialmente as de $n^{\circ} 53 / 1985$ e $n^{\circ} 116 / 1999$, citadas através de doutrina invocada.

Assim sendo, evidencia-se que esse movimento de partilha de fontes e experiências entre os Tribunais do mundo, traduzida por Antoine Garapon e Julie Allard (2005, p. 9) como comércio entre juízes, representa não só a acolhida de uma rede de trocas (intercâmbios), mas uma forma de sociabilidade nascida do desejo de estabelecer relações sólidas e corteses advindas de uma dependência recíproca dos Homens em buscar na experiência do outro o sustentáculo à sua decisão, a fim de que lhe proporcione maior legitimidade e aprovação. Não significa, portanto, um governo de juízes, nem o início de um Direito único e universal, mas alarga a comunidade jurídica de modo a formar uma comunidade de princípios. Esta última, por conseguinte, serve de referência global aos magistrados de modo a fazer com que tenham a possibilidade, e não a obrigação, de utilizar no caso concreto os mesmos princípios de justiça defendidos em outros países (GARAPON; ALLARD, 2005, p. 82).

Desse modo, esse intercâmbio entre juízes, embora notadamente argumentativo, implica um partilhar e um "assumir a responsabilidade pelos problemas e pelas soluções e já não simplesmente de enunciar as normas, os conceitos e as doutrinas" (GARAPON; ALLARD, 2005, p. 84). É reconhecer que as decisões proferidas sob circunstâncias de interesse geral são fundadas em determinados princípios de moralidade política 
considerados corretos (DWORKIN, 2000-2001, p. 3 - 6) e humanitariamente fundados (como, por exemplo, a proibição à tortura e aos trabalhos considerados desumanos), tendo nos princípios democráticos e republicanos seu esteio e, nos objetivos gerais da nação, seu fim.

Por fim, pode-se sustentar que o magistrado, enquanto órgão do Poder Judiciário investido de poder jurisdicional, constitui-se em verdadeiro motor de promoção dos Direitos Humanos quando atua no âmbito de um processo de modelo coletivo, pois lhe é conferida uma postura ativa, de participação cidadã. Isso não significa que a partir de então lhe ficará permitido julgar para além ou aquém da lide proposta ou que poderá atuar de ofício em todos os atos processuais, mas sim que sua atuação não mais será de mero condutor do processo, de espectador. Enquanto cidadão, o magistrado constitui-se em partícipe social e sua atuação deve garantir que como tal não fechará seus olhos às desigualdades e necessidades sociais, permitindo acesso e paridade a todos os cidadãos e instituições representativas no processo, intérpretes solidários da norma. Sua decisão, portanto, deverá ser em prol às reivindicações e necessidades sociais, tendo sempre em vista a concretização da justiça num procedimento célere, eficiente e plural.

\section{CONSIDERAÇÕES FINAIS}

A internacionalização do Direito, com base no que se procurou evidenciar neste artigo, principalmente por que impulsionada pela concepção universalista dos Direitos Humanos, pode-se sustentar que é um movimento benéfico em prol da concretização dos direitos e garantias fundamentais do cidadão nacional, pois the garante o acesso pleno a todos os direitos que lhe fundamentam enquanto ser humano. Além disso, que "o movimento à abertura que a constitucionalização do processo imprime" (SALDANHA; ESPINDOLA, 2008, p. 51), alarga o número de atores jurídicos e intérpretes da Constituição, impregnando o processo e os julgadores de valores democráticos e republicanos.

Ademais, a troca de informações entre tribunais, como a que ocorreu na ADI 3510, abre um mundo de possibilidades que só se evidencia em uma sociedade aberta dos intérpretes da Constituição. E, além disso, essa circulação de decisões e experiências serve como esteio ao esforço de bem julgar, porque além de reforçar a universalidade dos Direitos Humanos, concretiza seu objetivo central: proteger o cidadão, independente de nacionalidades, através da busca à fonte mais benéfica para 
melhor lhe prestar a tutela jurisdicional. Em suma, como ensinam Garapon e Allard (2005, p. 83), é “o único modo de tornar efetivo o conceito de direitos fundamentais".

Assim, esse compartir de interpretações evidencia um recíproco viver a norma interpretada, sendo o jurista também atingido pela prestação jurisdicional. Desse modo, cumpre ao magistrado uma postura ativa enquanto cidadão do Estado Democrático de Direito, pois lhe cabe, além da função política que exerce, em razão dessa nova postura cidadã, uma busca pela efetiva promoção dos direitos que fundamentam a sua própria existência e a dos demais, assim como uma busca pela promoção de uma paz estável na comunidade como um todo através da primazia dos Direitos Humanos.

É esse, por fim, o juiz do Estado Democrático de Direito, pois privilegia a democracia e equaliza a ordem jurídica nacional, internacional e estrangeira sob o prisma da primazia da dignidade humana, sanando toda e qualquer dificuldade à concretização dos Direitos Humanos frente à internacionalização do Direito. Assim, não se vê como apenas um intérprete da norma, mas como um participante ativo da sociedade e um agente impulsionador dos direitos e garantias do cidadão, promovendo a paz e concretizando os objetivos de um Estado republicano e plural.

\section{REFERÊNCIAS BIBLIOGRÁFICAS}

ARENDT, Hannah. Entre o passado e o futuro. 3. ed. São Paulo: Perspectiva, 1992.

ARENHART, Sérgio Cruz; MARINONI, Luiz Guilherme. Processo de Conhecimento. 7 ed. rev. e atual. São Paulo: Editora Revista dos Tribunais, 2008. (Curso de Processo Civil, vol. 2)

BECCARIA, Cesare. Dos delitos e das penas. 2. ed. São Paulo: Martin Claret, 2007.

BICUDO, Hélio. O Desafio dos Direitos Humanos. In: ALBUQUERQUE, Paulo; KEIL, Ivete; VIOLA, Solon (org.). Direitos Humanos: alternativas de justiça social na América Latina. São Leopoldo: Editora Unisinos, 2002.

BOBBIO, Norberto. A Era dos Direitos. Rio de Janeiro: Campus, 1992.

BRITTO, Carlos Ayres. Relatório e voto na ADI 3510. In: Íntegra do voto do ministro Carlos Ayres Britto na ADI sobre a Lei de Biossegurança. NOTÍCIAS STF, Brasília, quarta-feira, 5 mar. 2008. Disponível em: < http://www.stf.jus.br/portal/cms/ verNoticiaDetalhe.asp?idConteudo=84384 >. Acesso em: 23 ago. 2009.

CALAMANDREI, Piero. Eles, os juízes, vistos por nós, os advogados. 7. ed. Lisboa: Clássica, 1990. 
DELMAS-MARTY, Mireille. Três desafios para um direito mundial. Rio de Janeiro: Lumen Juris, 2003.

DWORKIN, Ronald. Uma questão de princípio. São Paulo: Martins Fontes, 20002001. (Justiça e direito)

GARAPON, Antoine; ALLARD, Julie. Os Juízes na Mundialização: a nova revolução do Direito. Lisboa: Instituto Piaget, 2005.

HÄBERLE, Peter. Hermenêutica Constitucional: a sociedade aberta dos intérpretes da constituição. Porto Alegre: Sergio Antonio Fabris, 1997

KRISCHKE, Jair. Desafios dos Direitos Humanos na América Latina. In: ALBUQUERQUE, Paulo; KEIL, Ivete; VIOLA, Solon (org.). Direitos Humanos: alternativas de justiça social na América Latina. São Leopoldo: Editora Unisinos, 2002.

LEWANDOWSKI, Enrique Ricardo. Voto na ADI 3510. In: Íntegra do voto do ministro Ricardo Lewandowski na ADI sobre Biossegurança. NOTÍCIAS STF, Brasília, quarta-feira, 28 mai. 2008. Disponível em: < http://www.stf.jus.br/portal/cms/ verNoticiaDetalhe.asp?idConteudo=89744 >. Acesso em: 23 ago. 2009.

MENDES, Gilmar Ferreira. Voto na ADI 3510. In: Íntegra do voto do ministro Gilmar Mendes na ADI sobre células-tronco. NOTÍCIAS STF, Brasília, segunda-feira, 2 jun. 2008. Disponível em: < http://www.stf.jus.br/portal/cms/verNoticiaDetalhe.asp? $\underline{\text { idConteudo }=90158}>$. Acesso em: 23 ago. 2009.

MELLO, Marcelo Pereira de. A perspectiva sistêmica na sociologia do direito: Luhmann e Teubner. Tempo Social [online]. 2006, vol.18, n.1, pp. 351-373. Disponível em: < http://www.scielo.br/scielo.php?script=sci_arttext\&pid=S0103-20702006000100 018\&lng=en\&nrm=iso >. Acesso em: 23 ago. 2009.

NORTHFLEET, Ellen Gracie. Voto na ADI 3510. In: Íntegra do voto da ministra Ellen Gracie na ADI sobre a Lei de Biossegurança. NOTÍCIAS STF, Brasília, quinta-feira, 6 mar. 2008. Disponível em: < http://www.stf.jus.br/portal/cms/verNoticiaDetalhe.asp ?idConteudo $=84420>$. Acesso em: 23 ago. 2009.

OLIVEIRA, Kelly. Ministro critica "judicialização da saúde". Agência Brasil, Brasília, 12 set. 2007. Disponível em: < http://www.agenciabrasil.gov.br/noticias/2007/09/ 12/materia.2007-09-12.28810710 41/view >. Acesso em: 17 de ago. 2009.

OLIVEIRA, Rita de Cássia Cartelli de; MOTTA, Ivan Dias. Conjecturas da Epistemologia Jurídica e Aspectos da Teoria da Linguagem. In: Revista Jurídica Cesumar, v. 8, n. 1, p. $35-48$, jan./jun. 2008.

PIOVESAN, Flávia. Direitos Humanos e Justiça Internacional: um estudo comparativo dos sistemas regionais europeu, interamericano e africano. 1. ed. 2. tiragem. São Paulo: Saraiva, 2007a.

Direitos humanos e o direito constitucional internacional. 8. ed., rev. ampl. e atual. São Paulo: Saraiva, 2007b. 
Princípio da complementariedade e soberania. Disponível em: $\langle$ http://www.dhnet.org. br/direitos/sip/tpi/textos/tpi_piovesan.html $>$. Acesso em: 06 ago. 2009.

ROCHA, Cármen Lúcia Antunes. Voto na ADI 3510. In: Íntegra do voto da ministra Cármen Lúcia Antunes Rocha sobre pesquisas com células-tronco embrionárias. NOTÍCIAS STF, Brasília, sexta-feira, 30 mai. 2008. Disponível em: < http://www.stf.jus.br/portal/cms/verNoticiaDetalhe.asp?idConteudo=90036 $>$. Acesso em: 23 ago. 2009.

ROCHA, Leonel Severo. Da Epistemologia Jurídica Normativista ao Construtivismo Sistêmico. Boletim da Faculdade de Direito. Universidade de Coimbra, v. 1, 2008, p. 1033-1065.

SALDANHA, Jânia Maria Lopes. Da Teoria Geral do Processo á Teoria da Tradução: um aporte da sociologia das ausências e das emergências. In: Lenio Luiz Streck; José Luis Bolzan de Morais. (Org.). Constituição, Sistemas Sociais e Hermenêutica. 1 ed. Porto Alegre: Livraria do Advogado, 2007, v. 4, p. 27-52.

; ESPINDOLA, Angela Araújo da Silveira. A jurisdição constitucional e o caso da ADIn 3.510: do modelo individualista - e liberal - ao modelo coletivo - e democrático - de processo. In: MARIN, Jeferson Dytz (Coord.). Jurisdição e processo: efetividade e realização da pretensão material. Curitiba: Juruá, 2008.

SANTOS, Boaventura de Sousa. Introdução à sociologia da administração da justiça. In: FARIA, José Eduardo. (org.). Direito e Justiça: a função social do judiciário. São Paulo: Editora Ática, 1997.

SARLET, Ingo Wolfgang. Direitos Fundamentais, Reforma do Judiciário e Tratados Internacionais de Direitos Humanos. In: CLÈVE, Clèmerson Merlin; PAGLIARINI, Alexandre Coutinho; SARLET, Ingo Wolfgang (Coord.). Direitos Humanos e Democracia. 1. ed. Rio de Janeiro: Forense, 2007.

SILVA, José Afonso da. Curso de direito constitucional positivo. 29. ed. São Paulo: Malheiros, 2007.

TRINDADE, Antônio Augusto Cançado. Apresentação. In: PIOVESAN, Flávia. Direitos humanos e o direito constitucional internacional. 8. ed., rev. ampl. e atual. São Paulo: Saraiva, 2007.

VIEIRA, José Ribas. A cidadania e a democracia: seus impasses no campo jurídico. In: MELLO, Marcelo Pereira de (Org.). Justiça e Sociedade: temas e perspectivas. São Paulo: LTr, 2001.

WOLKMER, Antonio Carlos. Elementos para uma crítica do estado. Porto Alegre: Sergio Antonio Fabris, 1990.

Pluralismo jurídico: fundamentos de uma nova cultura no direito. São Paulo: Alfa-Omega, 1994. 